\title{
Planos Diretores do Município de Belém (PA) e a Questão dos Rios Urbanos
}

\author{
City's Master Plan of Belém (PA) and Water Urban Rives \\ Principales Planes del Municipio de Belém (PA) y la Cuestión de los Ríos Urbanos
}

Recebido: 06/08/2021 | Revisado: 14/08/2021 | Aceito: 17/08/2021 | Publicado: 20/08/2021

Helena Lúcia Zagury Tourinho

ORCID: https://orcid.org/0000-0001-7588-1680 Universidade da Amazônia, Brasil

E-mail: helenazt@uol.com.br

Maria do Socorro Bezerra Lopes ORCID: https://orcid.org/0000-0003-1650-4724

Universidade da Amazônia, Brasil E-mail: soclopes@gmail.com

Márcia Rafaela Souza Vieira

ORCID: https://orcid.org/0000-0003-4229-8258 Universidade da Amazônia, Brasil

E-mail: mrafaelaasouzaa@gmail.com

Ana Carla Leite Carvalho Cabral

ORCID: https://orcid.org/0000-0002-1735-1320

Universidade da Amazônia, Brasil

E-mail: calincarvalho@gmail.com

\begin{abstract}
Resumo
Os rios são importantes condicionantes da morfologia urbana, dos usos e da ocupação do solo no território. Baseado em revisão bibliográfica e documental, bem como em informações cartográficas e dados socioeconômicos analisados em uma ferramenta de geoprocessamento, o artigo discute os papéis e funções dos rios urbanos nos planos diretores elaborados pós Constituição Federal (1988), em Belém-PA, uma metrópole amazônica. Mostra que, em Belém, o vínculo da ocupação urbana com os cursos d'água, historicamente, vem sendo marcado por relações de conciliação e conflitos ambientais. Nos Planos Diretores de 1993 e 2008, destaca os enfoques dos rios urbanos a partir do saneamento ambiental, da habitação, da mobilidade e da requalificação da paisagem para fins de lazer e turismo. Conclui que a ausência de discussão ampla das interfaces morfológica, ambiental e funcional dos rios urbanos, resulta na proposição de diretrizes amplas e segmentadas e proposições de ações setoriais voltadas sobretudo a obras, ora de saneamento básico, ora de urbanização de orla, ora de habitação, a grande maioria não implementadas. Por fim, sugere a necessidade de superar tais barreiras, ressaltando a importância dos planos diretores na definição da função social da cidade e, portanto, dos rios urbanos.
\end{abstract}

Palavras-chave: Rios urbanos; Plano diretor; Planejamento urbano; Saneamento ambiental; Belém.

\begin{abstract}
Rivers are important determinants of urban morphology, land use and occupation in the territory. Based on a bibliographical and documental review, as well as cartographic information and socioeconomic data analyzed in a geoprocessing tool, the article discusses the roles and functions of urban rivers in the city's master plans prepared after the 1998 Brazilian Federal Constitution, in Belém-PA, an Amazon metropolis. It shows that, in Belém, the link between urban occupation and watercourses has historically been marked by relationships of conciliation and environmental conflicts. In the 1993 and 2008 Master Plans, it highlights the approaches to urban rivers based on environmental sanitation, housing, mobility and the requalification of the landscape for leisure and tourism purposes. It concludes that the absence of a broad discussion of the morphological, environmental and functional interfaces of urban rivers, results in both broad and segmented guidelines propositions and sectorial actions propositions focused mainly on works, sometimes on basic sanitation, sometimes on waterfront urbanization, sometimes on housing, the vast majority not implemented. Finally, it suggests the need to overcome such barriers, emphasizing the importance of city's master plans in defining the social function of the city and, therefore, of urban rivers.
\end{abstract}

Keywords: Urban rivers; City’s master plan; Urban planning; Environmental sanitation; Belém.

\section{Resumen}

Los ríos son determinantes importantes de la morfología urbana, el uso del suelo y la ocupación del territorio. Basado en una 
revisión bibliográfica y documental, así como información cartográfica y datos socioeconómicos analizados en una herramienta de geoprocesamiento, el artículo discute los roles y funciones de los ríos urbanos en los planes maestros elaborados a partir de la Constitución Federal (1988), en Belém-PA, un Metrópolis amazónica. Muestra que, en Belém, el vínculo entre ocupación urbana y cursos de agua ha estado históricamente marcado por relaciones de conciliación y conflictos ambientales. En los Planes Directores de 1993 y 2008 destaca los acercamientos de los ríos urbanos basados en el saneamiento ambiental, la vivienda, la movilidad y la recalificación del paisaje con fines de ocio y turismo. Se concluye que la ausencia de una amplia discusión de las interfaces morfológicas, ambientales y funcionales de los ríos urbanos, da como resultado la proposición de lineamientos amplios y segmentados y propuestas de acciones sectoriales enfocadas principalmente en obras, a veces en saneamiento básico, a veces en urbanización frente al mar, a veces sobre vivienda, la gran mayoría no implementada. Finalmente, sugiere la necesidad de superar tales barreras, enfatizando la importancia de los planes maestros en la definición de la función social de la ciudad y, por ende, de los ríos urbanos.

Palabras clave: Ríos urbanos; Plan maestro; Planificación urbana; Saneamiento ambiental; Belém.

\section{Introdução}

Rios, córregos e riachos são os caminhos das águas doces que buscam um nível mais baixo de repouso. E dessa forma vão desenhando o seu percurso em linha ao sabor da topografia, conectando montanhas e planícies, florestas e mares, conectando enfim diferentes fisionomias paisagísticas (...). O rio é assim uma estrutura viva, e portanto, mutante. É principalmente uma estrutura fluída, que pela sua própria natureza se expande e se retrai, no seu ritmo e seu tempo próprio. (Costa, 2006, p.10)

A partir da década de 1980, no bojo do crescimento da preocupação com a questão ambiental, amplia-se o debate sobre a problemática dos rios urbanos. No artigo 20, inciso III, da Constituição, se estabelece que seja bens da União os lagos, rios e quaisquer correntes de água em terrenos de seu domínio, ou que banhem mais de um Estado, sirvam de limites com outros países, ou se estendam a território estrangeiro ou dele provenham, bem como os terrenos marginais e as praias fluviais. Aos bens dos Estados a Constituição, no artigo 26, I, estabelece “as águas superficiais ou subterrâneas, fluentes, emergentes e em depósito” (Constituição do Brasil, 1988).

A Lei n. 9.433 de 8 de janeiro de 1997 que instituiu a Política Nacional dos Recursos Hídricos, em consonância ao estabelecido na Constituição, deixou expresso que constitui como um dos fundamentos dessa política nacional considerar a água como bem de domínio público e a necessidade de integração da gestão dos recursos hídricos com as gestões ambiental e do uso do solo (Lei n. 9.433, 1997).

No que diz respeito à política urbana, a Constituição Federal (1988), em seu art. 182, definiu o Plano Diretor como o instrumento básico da política de desenvolvimento e de expansão urbana, sendo este obrigatório para cidades de mais de 20.000 habitantes, dentre outras. É no plano diretor, que, de acordo com o Estatuto das Cidades (Lei n ${ }^{\circ} 10.257$ de 10 de julho de 2001 ) se define a função social da propriedade (Constituição do Brasil, 1988; Lei nº10.257, 2001). Também é nesse documento que, de acordo com a Lei $n^{\circ} 12.608$ (2012), os Municípios incluídos no cadastro nacional de municípios com áreas suscetíveis à ocorrência de inundações bruscas ou processos geológicos ou hidrológicos correlatos devem contemplar: os parâmetros de parcelamento, uso e ocupação do solo, de modo a promover a diversidade de usos e a contribuir para a geração de emprego e renda; e as medidas de drenagem urbana necessárias à prevenção e à mitigação de impactos de desastres (Lei no 12.608, 2012).

O município de Belém, situado na região norte do Brasil possui uma população de 1.499.641 pessoas, segundo estimativa do IBGE para o ano de 2020. Com área de 1.059,46 km² o município é composto por uma porção continental (34,36\% da área total) e 39 ilhas (65,64\% da área total), sendo que, na parte continental, são encontradas 14 bacias de drenagem. (Figura 1). 
Figura 1: Bacias Hidrográficas do Município de Belém.

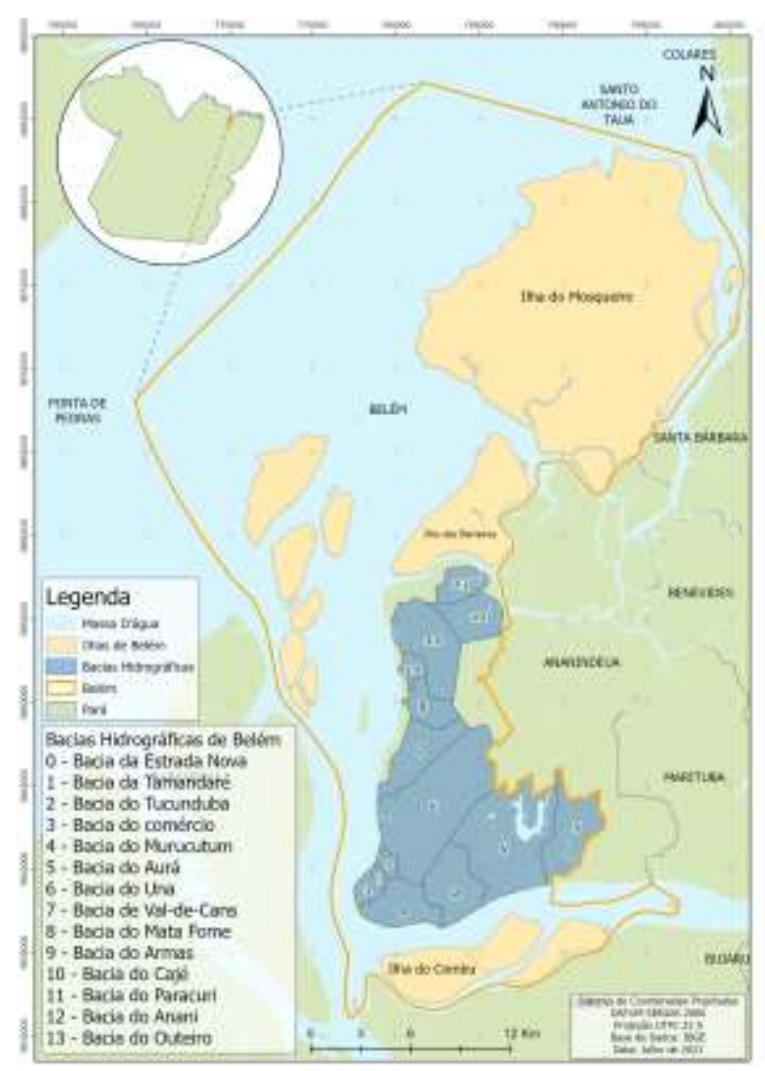

Fonte: Autores (2021).

As ilhas, também, são entrecortadas por diversos cursos d'água, conhecidos na região pela denominação de igarapés (Belém, 2019). Eles atravessam a cidade e formam bacias como a do Una, Tucunduba e São Joaquim. Eles permitem o fluxo de pessoas, de mercadorias, de sonhos e realizações; de pessoas pertencentes a grupos sociais de várias origens, como um mosaico de agências sociais que interagem e exprimem a singularidade da cidade (Castro, 2019).

Para Macedo (2003), apesar de Belém estar em uma região predominantemente abundante de água doce, pode vir a sofrer com o comprometimento de seus recursos hídricos, necessitando de medidas urgentes que venham conscientizar a população e direcionar as ações de gestão para solução de situações conflitivas de disponibilidade qualitativa das águas comprometidas em suas bacias urbanas.

Ao longo do tempo diversas mudanças foram ocorrendo nas paisagens de Belém relacionadas ao fluxo das águas. Seus canais e rios urbanos foram aterrados, assoreados ou desviados de seus cursos por diferentes processos de intervenção governamental ou privada, redefinindo a aparência e a morfologia da cidade. As dinâmicas humanas com práticas predatórias estão fragilizando ecossistemas importantes como aqueles de zonas costeiras, lagos, rios, igarapés, igapós e mangues que têm desaparecido mais rapidamente que outros biomas de floresta natural (Castro, 2019).

Conti e Silva (2017) alertam que ações de intervenção nos cursos d'agua consideradas de alto impacto devem ser evitadas. Todavia, não é isso que acontece. À revelia do indicado pela legislação, e no caminho inverso ao estabelecimento para que se tenha um ambiente urbano adequado, a morfologia dos córregos é alterada. Por mais que se argumente que tais modificações são 
acompanhadas de contrapartidas, o ônus é da população como um todo.

Tais observações convidam a refletir sobre como os rios urbanos estão sendo tratados no planejamento das metrópoles amazônicas. Se estão sendo considerados levadas em conta as pressões que a urbanização e o aumento demográfico exercem sobre os recursos hídricos e, por conseguinte, sobre a qualidade e a preservação desse recurso natural. Diante do exposto, este artigo investiga, a partir de pesquisa bibliográfica e documental, "como" os planos diretores de Belém aprovados após a Constituição Federal (1988) apreenderam os rios urbanos e propuseram neles intervir. Procura identificar as principais abordagens realizadas e suas modificações no que tange à questão ambiental, esta vista como resultante da relação dialética que se estabelece entre sociedade e recursos naturais, relação essa que resulta, em áreas urbanas, em espaços socialmente produzidos.

O artigo está estruturado em três partes, além desta introdução. Após apresentar, suscintamente, os procedimentos metodológicos usados, traça um breve histórico das inserções dos cursos d'água na malha urbana e das intervenções nas bacias hidrográficas belenenses. Na sequência, apresenta e discute como os rios urbanos são enfocados no Plano Diretor do Município de Belém de 1993 - Lei n. ${ }^{\circ} 7.603$ (1993) e no Plano Diretor do Município de Belém de 2008 - Lei n. 8.655 (2008). Por fim, expõem-se as conclusões e referências bibliográficas utilizadas.

\section{Metodologia}

A discussão sobre a importância e os papéis dos rios urbanos no planejamento e no ordenamento espacial das cidades contemporâneas, assim como a identificação da maneira pela qual os rios urbanos de Belém vêm sendo tratados, historicamente, nas intervenções urbanísticas e no planejamento urbano, foi realizada com base em pesquisa bibliográfica e documental.

Em termos específicos, foram analisados, mais detalhadamente, os documentos de planejamento urbano de cunho globalizante pós Constituição Federal (1988), ou seja, os Planos Diretores do Município de Belém (PDMBs) de 1993 Lei n. ${ }^{\circ} 7.603$ (1993) e de 2008 Lei n 8.655 (2008). Para esse período, vale destacar, não foram enfocados planos, programas ou projetos setoriais de saneamento ambiental, tais como planos específicos de macrodrenagem de bacias, projetos urbanísticos para áreas de orla ou envolvendo cursos de água, que tiveram caráter pontual e/ou que estiveram vinculados aos marcos conceituais do planejamento estratégico promovido pela política urbana neoliberal.

Para articular as abordagens adotadas nos planos tratados com a dinâmica socioespacial, foram utilizadas informações cartográficas das bacias hidrográficas, bem como dados socioeconômicos do IBGE, desagregados por setor censitário, processados utilizando-se ferramenta de geoprocessamento.

\section{Resultados}

\subsection{Belém - Cidade com rios e igarapés}

As primeiras (e muitas) cidades brasileiras nasceram às margens do rio, pois, como destaca Costa (2006, p. 10), os rios "tinham muito a oferecer, além de água: controle do território, alimentos, possibilidade de circulação de pessoas e bens, energia hidráulica, lazer, entre tantos outros" (Costa, 2006, p. 10).

No caso da Amazônia, dos primórdios da ocupação colonial portuguesa até a década de 1960, o surgimento e o crescimento de grande parte das cidades, de uma forma ou de outra, estiveram associados à presença e à configuração da malha fluvial, seja em função do papel que os rios desempenhavam para o abastecimento e as trocas de produtos regionais, seja pela influência que exerceram na estruturação da rede de cidades e dos espaços intraurbanos, e na vida cotidiana da população (Becker, 
1990; Corrêa, 2006; Oliveira, 2006; Tourinho, 2011; Trindade \& Tavares Junior, 2008).

Belém é um exemplo disso. A cidade está localizada na confluência da baía do Guajará com o Rio Guamá e é entrecortada por diversos rios, igarapés e canais. Embora a relação com os rios venha se alterando ao longo do tempo, é evidente o papel econômico, simbólico e morfológico desse elemento natural na estruturação, usos e ocupação do espaço urbano (Penteado, 1968; Corrêa, 1989; Ponte, 2007). A relação da sociedade belenense com os rios, todavia, tem se dado de maneira conflituosa. Ocupações irregulares, lançamento de dejetos e resíduos domésticos e industriais, veiculação de doenças, ocorrência de enchentes, são apenas alguns exemplos de manifestação desses conflitos.

As primeiras intervenções de maior monta nos rios de Belém com fins de urbanização remontam ao século XVIII, quando teve início o dessecamento do Igarapé do Piri, “alagado que possuía 1.320 metros de largura, por 660m de comprimento. A área da cidade, na época, media 1.500 metros de comprimento por 750m de largura" (Santos, 2016, p.2). Essa obra foi ampliada a partir de 1803 estendendo-se até o Arsenal de Marinha. Com o ensecamento do Piri, rompia-se com a tradição do urbanismo colonial português de adaptação da malha urbana ao sítio e iniciava-se a era da racionalização do traçado e da supressão de meandros de leitos de igarapés (como são chamados os pequenos rios urbanos na Amazônia), de modo a acelerar o escoamento das águas e afastar os dejetos da paisagem.

Ainda na primeira metade do século XIX foi aterrada a área frontal da cidade, voltada para a Baía do Guajará, no trecho localizado entre a Igreja das Mercês e o Ver-o-Peso. A partir do final do século XIX, com o advento da economia da borracha, para viabilizar a construção do porto destinado à atracação de embarcações de maior porte, foram aterrados diques e vários igarapés (pequenos canais naturais), a exemplo da Doca do Reduto, gerando acrescidos de Marinha onde hoje se encontram, dentre outros, o Boulevard Castilho França e a rua Municipalidade (Arruda, 2003).

Sarges (2002) destaca o caráter autoritário da administração municipal do Intendente Antônio Lemos, que no final do século XIX, associava o discurso do embelezamento urbano ao discurso higienista próprio e prevalecente nas ações de renovação urbana brasileiras. Nesse contexto, normativas urbanísticas procuraram disciplinar o escoamento das águas de chuva das coberturas das edificações para que não fossem dispostas no leito das vias, diques e contenções em alvenaria de pedra ou blocos foram construídos para limitar o avanço das águas, e aterros/acrescidos produziram solo para dar lugar a estruturas portuárias, suprimindo bancos de areia e praias.

As intervenções urbanas no espaço belenense mediante o aterramento ou a canalização dos cursos d'água prosseguiram, com a construção do Dique de Belém e a retificação e o tratamento dado ao canal da Doca de Souza Franco.

Como se pode constatar, o modelo predominante de como a cidade tem se relacionado com suas águas, desde então, se caracteriza pela sujeição absoluta da natureza aos interesses humanos, e se fundamenta e justifica, em grande medida, no discurso higienista sanitarista. Esse modelo não é uma singularidade de Belém. Como ressalta Costa (2006, p. 10), a forma de enfrentar os conflitos decorrentes da relação entre rios e urbanização por meio da promoção de "drásticas alterações na estrutura ambiental dos rios, onde, em situações extremas, chega-se ao desaparecimento completo dos cursos d'água da paisagem", foi utilizada intensamente em todo o Brasil. Hoje, soluções como a retificação, o revestimento do leito vivo com calhas de concreto e a substituição das margens vegetadas por vias asfaltadas, segundo essa autora, não são mais aceitáveis, quer pela sua fragilidade ambiental, quer pela pouca eficiência no controle de enchentes.

Segundo Pontes (2015), do final do século XIX às primeiras décadas do século XX, na cidade de Belém, a abordagem das águas torna-se, progressivamente, técnica, resultando em instalação de portos, retificação de canais, construção de taludes impermeáveis, aterramento de áreas alagáveis, remoções de moradias e no avanço da implantação de redes de infraestrutura. Para 
esse autor, a partir dessa fase, cursos d'água, além de veículos (condutores de dejetos, de matéria, inclusive mercadorias), se tornam substâncias (para produzir reações, de limpeza, sulfactação, diluição) e, por fim, paisagem, com a requalificação de orlas como espaços para o turismo e lazer fazendo surgir diferenciais de valor do solo urbano a elas relacionados.

A partir das últimas décadas do século XX, a cidade assiste à implementação de um conjunto de obras com a finalidade de fomentar os usos de lazer e turísticos nas orlas da baía do Guajará e do rio Guamá (Projeto Estação das Docas, Ver-o-Rio e Portal da Amazônia). Essas intervenções, junto à ideia do saneamento ambiental, exploram a paisagem fluvial enquanto objeto de contemplação e de marketing urbano e, no caso de Belém, ainda não foram interiorizados, nem contemplaram as margens dos rios e igarapés que atravessam áreas pobres.

O processo de urbanização e de intervenção do homem no ambiente registrado nas últimas décadas, principalmente nos ambientes costeiros, tem exposto a sociedade a riscos e vulnerabilidades associadas ao ambiente, que são agravados pela condição social (Carvalho, 2015). Vitale (2015) destaca que, quando as medidas estratégicas de planejamento e gestão dos recursos urbanos ocorrem de forma articulada, é possível mitigar a pressão sobre os recursos disponíveis e melhorar os sistemas relacionados à água, como o saneamento básico. Nesse contexto, para resolver problemas urbanos e ambientais decorrentes do crescimento e da densificação populacional as políticas públicas precisam estar integradas.

Para Mendonça (2008) a questão da gestão dos recursos hídricos nas cidades brasileiras não pode ser tratada de forma desvinculada da questão da habitação e da ocupação do território. Para esse autor o risco se define como um produto combinado, ligado tanto às ciências da natureza quanto às ciências da sociedade. A vulnerabilidade decorre, então, de uma miríade de fatores que tornam grupos mais ou menos suscetíveis aos impactos derivados de riscos diversos que se formam nos contextos urbanos.

Braga, Barbosa e Almeida (2014) ao considerarem o processo de crescimento urbano de Belém, mostram que a pressão exercida sobre os cursos d'água é histórica, sendo observada já desde o fim da escravidão e de a era Pombalina, quando certa quantidade de pobres se fixou na cidade, ocupando áreas às margens dos cursos hídricos. A instalação de moradias em áreas alagáveis ou alagadas, formando as chamadas "ocupações das baixadas", contudo, só foi intensificada a partir da década de 1950, quando foram desativadas antigas vacarias localizadas próximas do centro urbano, e essas áreas passaram a abrigar residências dos segmentos mais pobres da população (Corrêa, 1989; Penteado, 1968).

Enquanto as margens do rio Guamá e da Baia do Guajará assumiam, progressivamente, funções comerciais e de suporte ao transporte de passageiros e mercadorias, mediante a instalação de portos e armazéns, as orlas desses rios nas periferias urbanas, assim como os leitos e calhas de rios, igarapés, canais localizados no interior do continente, se tornavam espaços da pobreza urbana, o que pode ser observado ao longo de grande parte da bacia do Tucunduba, por exemplo (Figura 2). 
Research, Society and Development, v. 10, n. 10, e591101019159, 2021

(CC BY 4.0) | ISSN 2525-3409 | DOI: http://dx.doi.org/10.33448/rsd-v10i10.19159

Figura 2: Palafitas e resíduos sólidos lançados às margens de rios da bacia do Tucunduba.

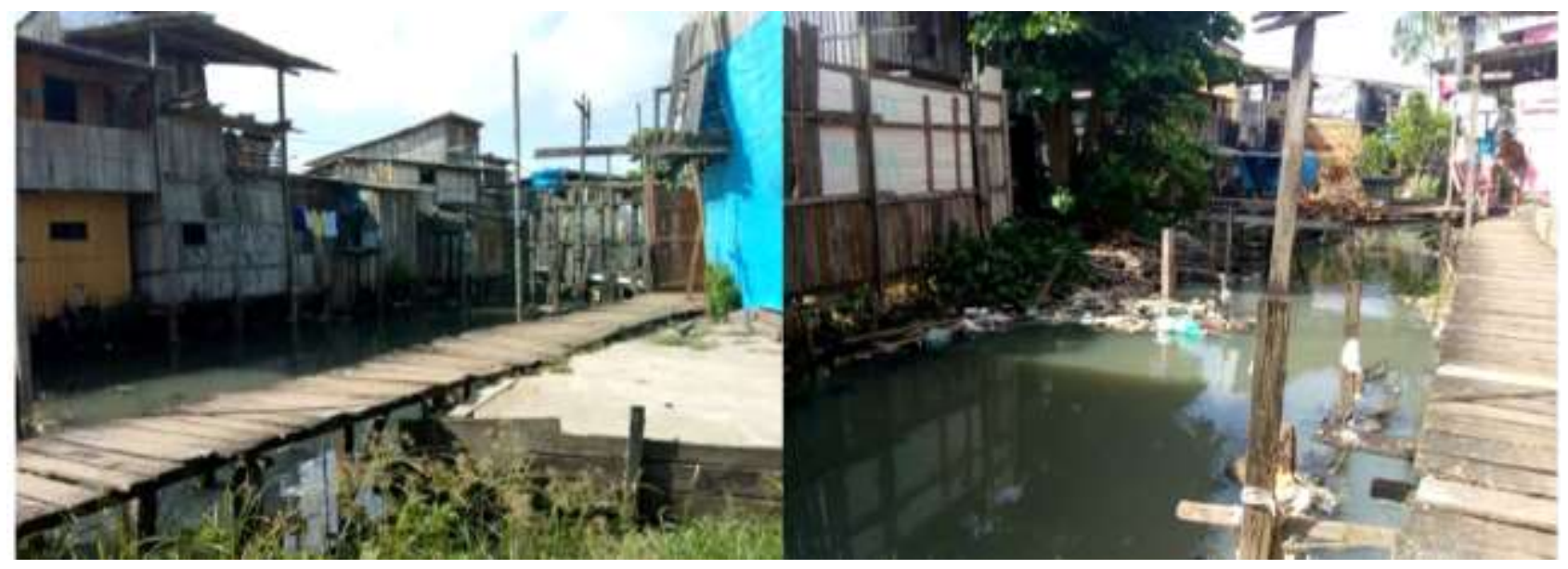

Fonte: Costa e Pontes (2019).

Costa e Pontes (2019), ao estudar a bacia do Tucunduba destacam as deficiências da infraestrutura urbana, especialmente de saneamento básico (drenagem, esgotamento sanitário, água encanada e coleta de lixo) para atender a população local e a alta concentração de habitações do tipo "palafitas", ao longo do canal. Esse quadro afeta, de forma direta, a qualidade de vida da população, contribuindo para os constantes alagamentos e transtornos verificados nos bairros que integram a referida bacia.

Cabe ressaltar que, o município de Belém, além de possuir 14 (quatorze) bacias hidrográficas, tem grande parte da área continental situada em terrenos de cotas altimétricas inferiores a 4 (quatro) metros, o que lhes impõem uma condição de terrenos alagados ou sujeitos a inundações intermitentes, como a que ocorreu em 09 de março de 2020 que causou o transbordamento de canais de várias áreas da cidade causando inúmeros transtornos à população (Figura 3).

Figura 3: Transbordamento de canais após fortes chuvas em março de $2020^{1}$.

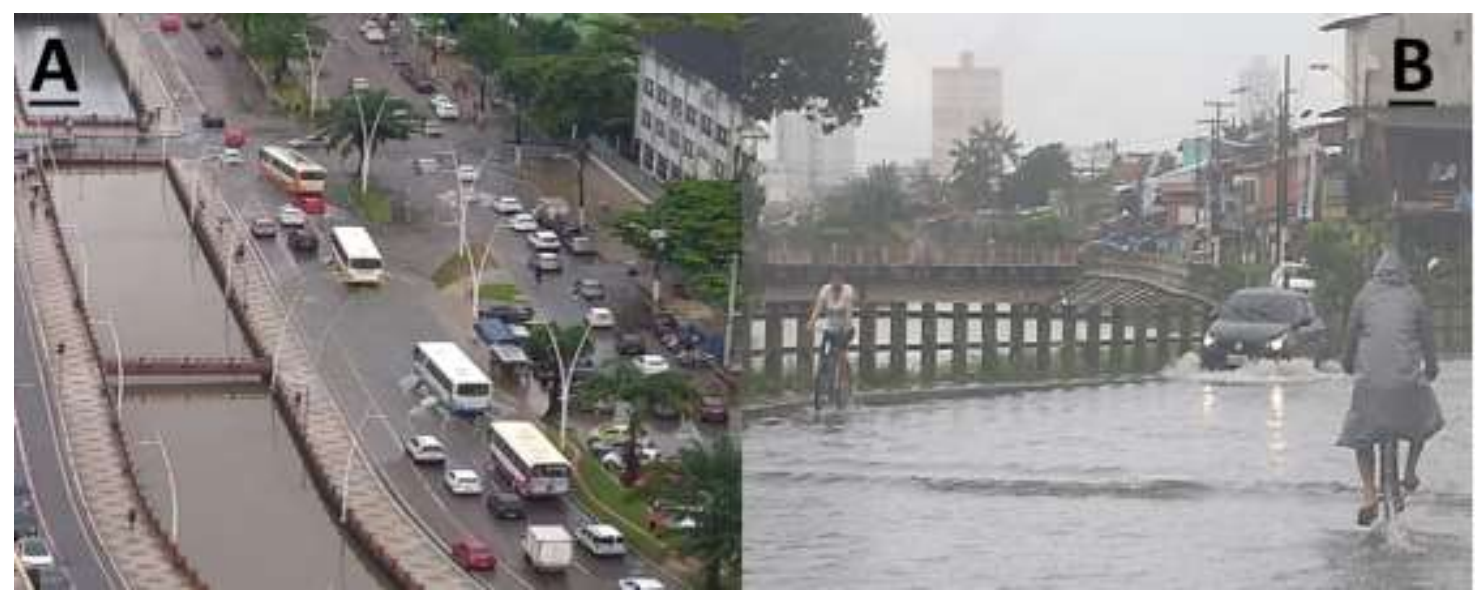

Fonte: Romanews (2020)

Os problemas decorrentes dos alagamentos se agravam quando coincidem as altas precipitações pluviométricas com os períodos diários de paralisação do sistema de escoamento provocados pela elevação dos níveis de marés.

1 A - Canal da Avenida Visconde de Souza Franco; B - Canal do Una 
Conforme Belém (2008), cerca de 12,6\% das unidades imobiliárias classificadas como assentamento precário de Belém se localizam em terrenos alagados ou alagáveis, sobre leitos de rios, canais, córregos, igarapés, taludes e barrancos, ou em cotas baixas.

As Figuras 4 e 5 mostram a configuração das áreas de bacias hidrográficas sujeitas a alagamentos e as distribuições espaciais de faixas de densidade populacional e de renda média dos chefes de domicílios, segundo os setores censitários de 2010 . A simples análise visual dessas imagens deixa clara a elevada correlação entre a presença de cursos de água e áreas alagáveis (cotas altimétricas inferiores a 4 metros) e a ocorrência de assentamento precários, ocupação densa e de baixa renda na área continental do município de Belém. Essa correlação foi construída historicamente e se mantém ainda hoje, a despeito das diversas intervenções já realizadas. Cabe então, analisar como os planos diretores mais recentes vêm enfrentando o problema dos rios urbanos.

Figura 4: Densidade Demográfica das Bacias Hidrográficas e Ilhas do Município de Belém em 2010.

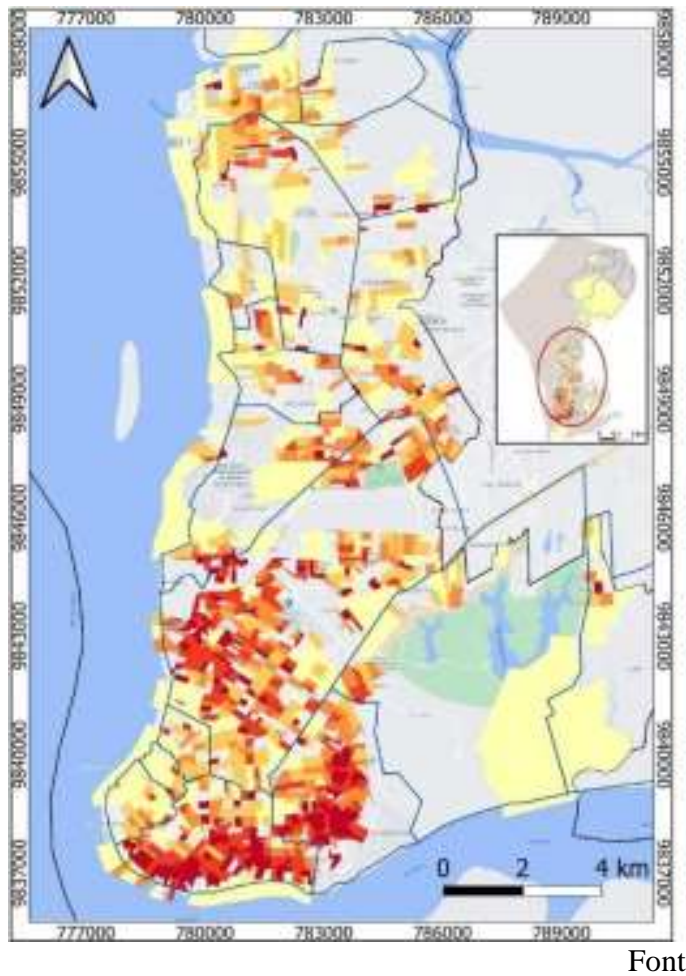

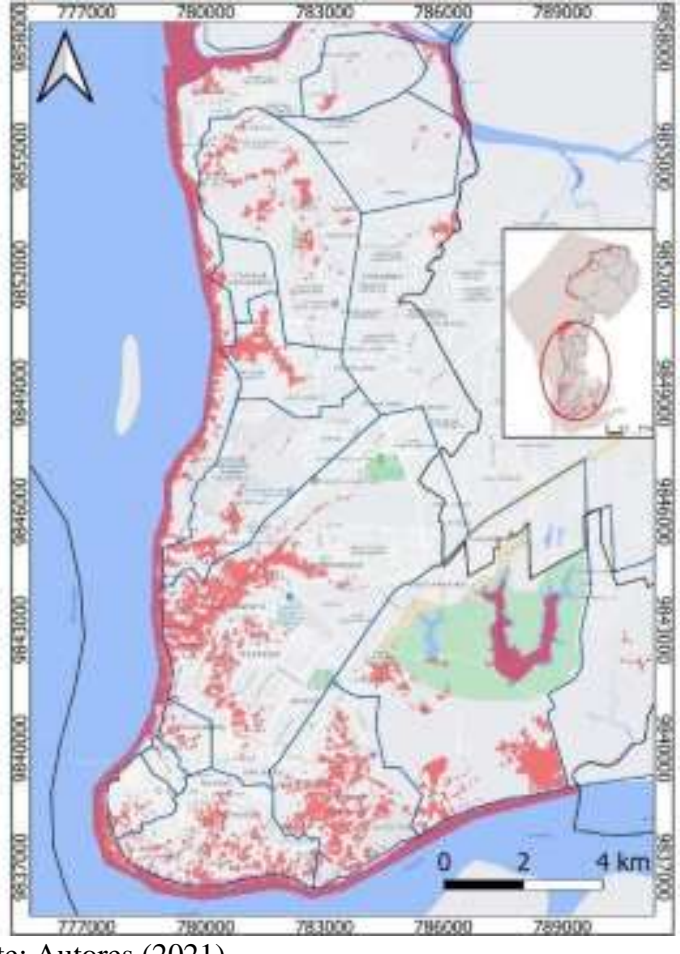

Fonte: Autores (2021).
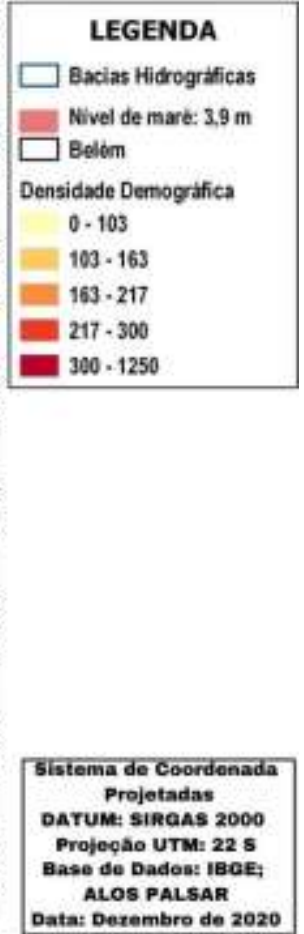
Figura 5: Renda Domiciliar por Setor Censitário de Município de Belém em 2010.
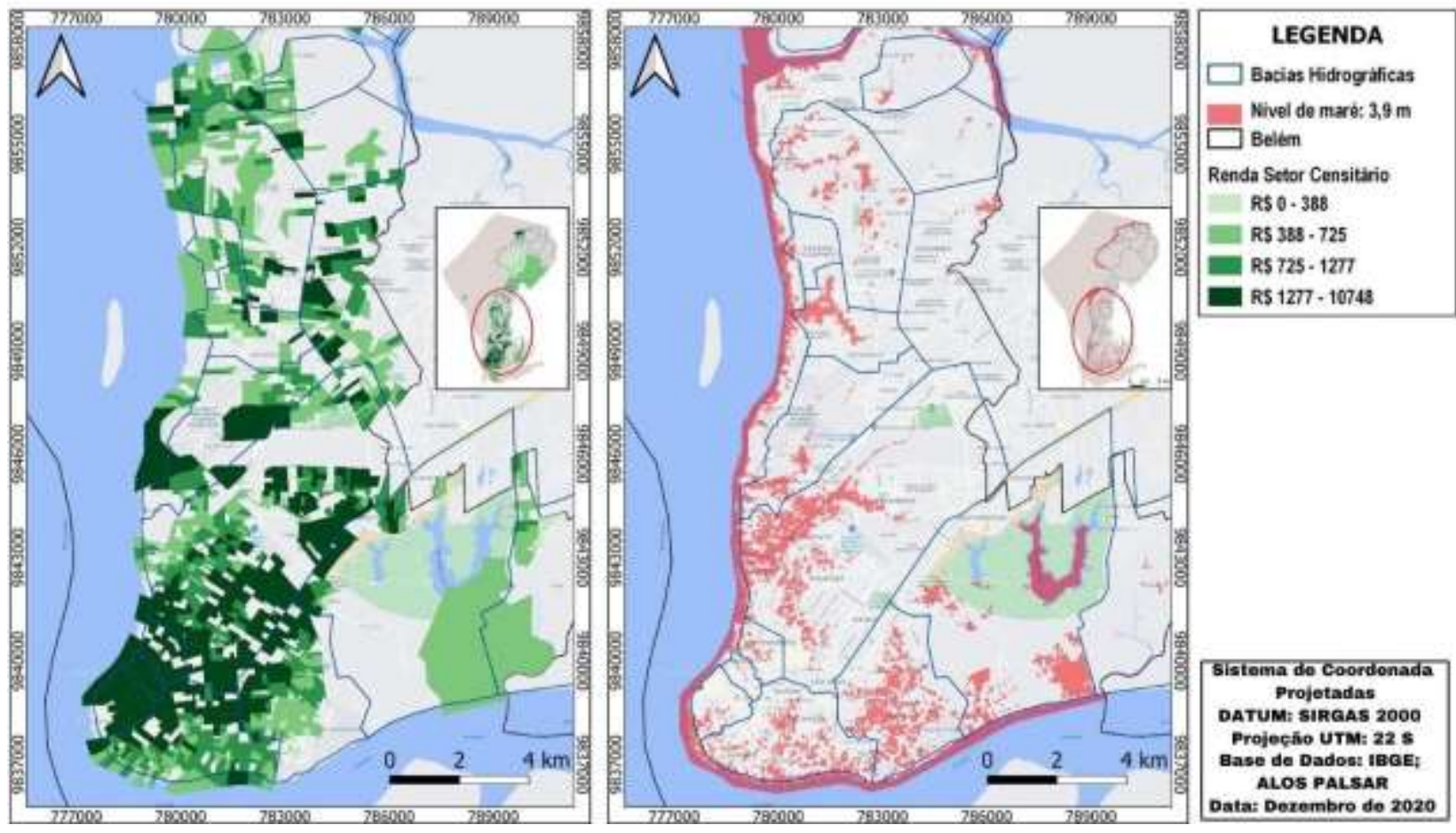

Fonte: Autores (2021).

\subsection{Plano Diretor do Município de Belém (PDMB) de 1993.}

Realizado após a mobilização pela Reforma Urbana e as aprovações dos capítulos referentes à Política Urbana nas Constituições Federal de 1988 e Estadual de 1989, o Plano Diretor do Município de Belém, a Lei n. 7.603 (1993), estabeleceu que o município promoveria o "desenvolvimento urbano considerando como critério, no planejamento e na execução das ações, a busca de soluções adequadas para os problemas de saneamento básico, para a promoção da qualidade de vida da população e da prevenção das condições sanitariamente adequadas" (Lei n. ${ }^{\circ}$ 7.603, 1993).

Os rios urbanos nesse contexto aparecem no plano com dois conteúdos: como recursos degradados que necessitam ser recuperados mediante a execução de obras que envolvem o remanejamento da ocupação irregular e/ou a realização de obras de saneamento básico; e como recurso paisagístico que confere identidade cultural local, a ser revalorizado com a criação de projetos de valorização da orla e de ampliação de "janelas" para o rio Guamá e para baía do Guajará".

Assim sendo, o plano propõe uma nova apropriação social para as paisagens fluviais que, sem superar a visão higienista das engenharias, se aproxima da perspectiva neoliberal que, segundo Vainer (2000), dentre outros, seleciona alguns pontos da cidade para, mediante intervenções urbanísticas, criar espaços e paisagens a serem vendidos e consumidos como mercadorias

No que concerne ao saneamento básico, o art. 80, VII do Plano define como "ações de drenagem urbana, limpeza urbana, abastecimento de água potável e esgoto sanitário, sendo as duas últimas ações de competência do governo municipal delegada ao governo estadual, e executada através de empresa concessionária” (Lei n. $\left.{ }^{\circ} 7.603,1993\right)$. Com isso, restaram como atribuições exclusivas municipais a drenagem e a limpeza urbanas.

Com fins de equacionamento dos problemas decorrentes das inundações, o Plano previu o planejamento e a implementação de ações do sistema de drenagem municipal em bacias e sub-bacias. Definiu bacia de drenagem a "área onde a 
contribuição das águas de precipitação pluviométrica se encaminha para cursos d'águas, que se reúnem em um mesmo ponto de escoamento para rios ou baías" (art. 86, § $1^{\circ}$ ); e, sub-bacia de drenagem como "a área onde as condições topográficas fazem com que as contribuições de águas resultantes das precipitações pluviométricas se encaminhem para o mesmo curso d'água" (art. 86, § $\left.2^{\circ}\right)\left(\right.$ Lei n. $\left.{ }^{\circ} 7.603,1993\right)$.

O PDMB de 1993 reconheceu que o intenso crescimento urbano e a ocupação irregular das margens dos cursos d'água trazem diversos prejuízos ambientais e para a população em geral. Com base nisso, estabeleceu como faixa de domínio dos canais a largura projetada dos canais propriamente ditos, somadas com as larguras das vias marginais de manutenção. No caso de cursos d'água naturais (rios e igarapés), determinou como faixa de domínio a largura do canal mais 33 (trinta e três) metros de cada lado, contados a partir das suas margens. Nessa faixa de domínio, proibiu a ocupação e a construção de edificações. Foi definido, também que, onde houvesse faixas já ocupadas, estas deveriam ser recuperadas mediante a remoção das edificações existentes, por meio do Programa de Remanejamento da Prefeitura Municipal de Belém (Lei n. ${ }^{\circ}$ 7.603, 1993).

Subjacente a essa proposição está a tese de que os assentamentos precários e irregulares nos cursos d'água e suas margens, ou seja, o problema habitacional, é o principal responsável pelos danos ambientais e paisagísticos verificados nos recursos hídricos urbanos, e que a solução para esse problema reside na remoção desses grupos para outras áreas, de cotas altas e secas, vista como condição necessária para a posterior recuperação das margens.

Para subsidiar as ações de planejamento e permitir condições adequadas para o escoamento das águas com potencial de acumulação necessário, notadamente nos períodos de coincidência entre chuvas e marés altas, o Plano previu, no art. 89, a aplicação de subsistemas de macrodrenagem, compreendendo a abertura e a retificação dos canais de drenagem e os revestimentos dos taludes laterais de todos os canais existentes. Para o caso de canais com foz em rios ou baías que sofressem influência direta das marés, estabeleceu que deveriam ser providos de sistema de barragem ou comportas, para controle das inundações (art. 93) (Lei n. ${ }^{\circ}$ 7.603, 1993).

Sobre a situação do esgotamento sanitário da grande Belém, o art. 112 determinou que os resíduos líquidos provenientes da limpeza de fossas sépticas, deveriam ser depositados em Estações de Tratamento de Esgotos Sanitários ou em local autorizado pelo órgão competente, ficando proibido o lançamento desses resíduos sem o tratamento adequado em canais, rios, igarapés, valas, galerias de águas pluviais ou aterros sanitários. O infrator ficou sujeito a penas previstas em lei regulamentar.

$\mathrm{O}$ art. 113 estabeleceu que o esgotamento sanitário deveria ser considerado a grande prioridade ambiental no município de Belém nos anos subsequentes, apontando que: apenas $6 \%$ da população era atendida pela rede coletora de esgotos, cujo lançamento era feito in natura por bombeamento para a baía do Guajará; $75 \%$ da população utilizava o sistema unitário constituído de fossas sépticas cujos efluentes, na maioria dos casos, eram interligados à rede de galerias pluviais; $19 \%$ da população lançava seus dejetos diretamente no solo. Assim, o plano assumiu que os cursos d água da cidade eram, quase todos, usados como esgotos a céu aberto, o que representava uma afronta ambiental aos cidadãos belenenses de todos os níveis sociais e dava a dimensão do desafio que estava subjacente ao atendimento das determinações que estabelecia.

A questão do esgotamento sanitário em cursos d'água também foi tratada no âmbito da Política de Meio Ambiente que instituiu, no art. 250, a "promoção dos estudos necessários ao estabelecimento de padrões de lançamento de resíduos líquidos nos mais diversos corpos receptores, bem como sua proteção contra usos inadequados que prejudiquem a qualidade das águas no município" (Lei n. $\left.{ }^{\circ} 7.603,1993\right)$.

Dado o processo de degradação ambiental que os cursos d'água apresentavam, considerando a relevância para o município e a forma como os recursos estavam inseridos no cotidiano das comunidades locais, o plano, no art. 143, apontou, 
dentre os objetivos da política de produção e organização do espaço urbano, o resgate e a valorização da fisionomia e a visualização dos elementos peculiares à cidade de Belém, como o rio, a baía, os igarapés, as mangueiras e a paisagem construída, especialmente os elementos representativos do patrimônio histórico-cultural. Especial ênfase foi dada, no mesmo artigo, "à recuperação da capacidade de ver e utilizar a orla do rio Guamá e da baía do Guajará pelo cidadão, resgatando, simbolicamente, as origens ribeirinhas de Belém". No art. 144 apresentou como diretriz: "resgatar áreas da orla fluvial de Belém para uso coletivo, com a criação e ampliação de "janelas" para o rio Guamá e para baía do Guajará" (Lei n. 7.603, 1993).

Essa diretriz reforça a exploração das orlas e dos rios como paisagem urbana, como espaços públicos de convívio social e de lazer e como elementos simbólicos da identidade amazônica. Esse movimento, como visto anteriormente, se materializa em intervenções urbanísticas realizadas nas margens da baía do Guajará e do rio Guamá, dentre as quais se destacam as obras da Estação das Docas, o Complexo Ver-o-Rio, o Mangal das Garças, o Portal da Amazônia e este último inaugurado no ano de 1999, (Figuras 6 e 7).

Figura 6: Intervenções na orla da baía do Guajará e no do rio Guamá.

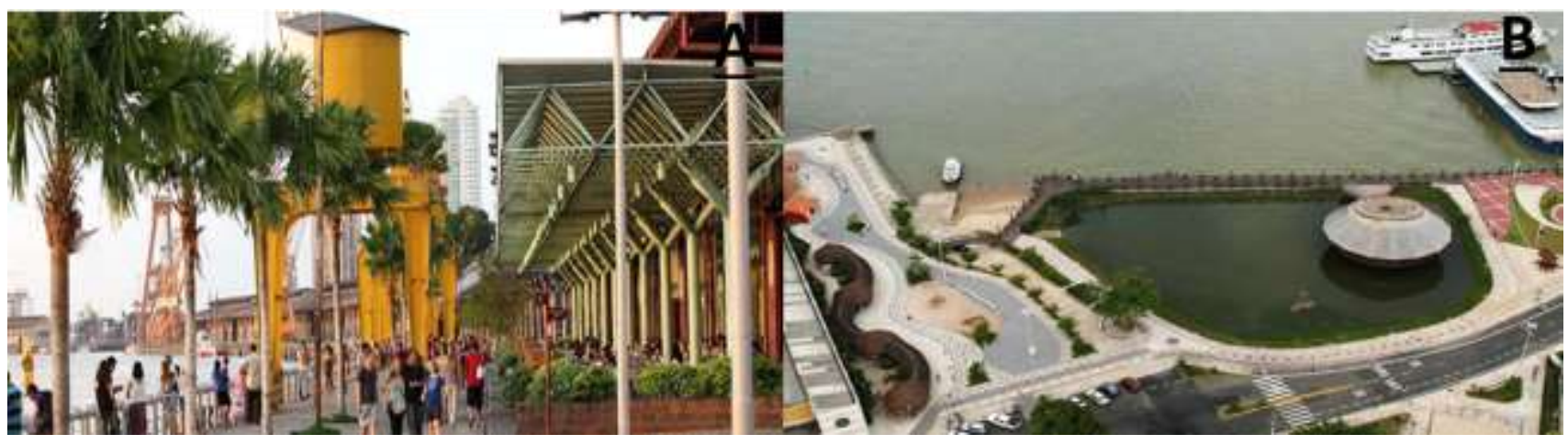

Fontes: A - Paraturismo (2018); B - Romanews (2019).

Figura 7: Intervenções na orla do rio Guamá.

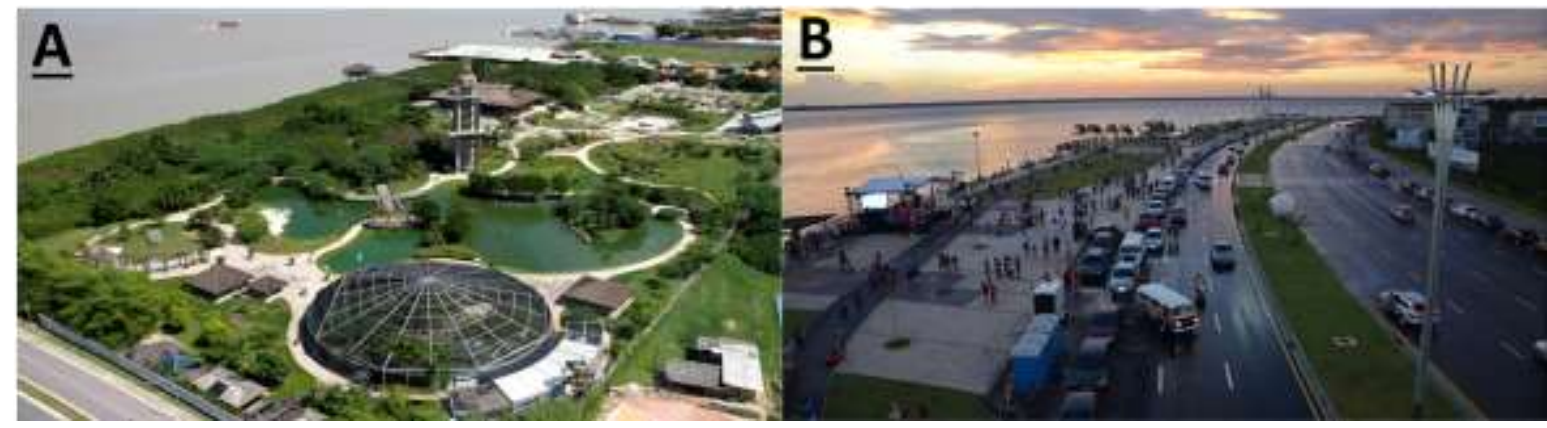

Fontes: A - Nascimento (2014); B - DOL (2019).

Observando o intenso crescimento urbano de Belém e sua estruturação o plano previu, ainda, que o uso industrial existente ao longo da orla da baía de Guajará e do rio Guamá deveria ser desestimulado e, por meio de operações urbanas, transferido para outros locais, mais adequados (Lei n. $\left.{ }^{\circ} 7.603,1993\right)$.

No que tange ao controle urbanístico do uso e da ocupação do solo no entorno dos mananciais de abastecimento de água, o plano, no art. 172, classificou a área do Utinga como Zona Especial de Preservação do Patrimônio Ambiental. Com isso, ficaram os: 
Projetos de parcelamento, reformas, demolições, ampliações, reconstruções ou novas edificações nas zonas especiais de preservação sujeitos à prévia aprovação do órgão municipal competente, devendo, em qualquer caso, respeitar de forma absoluta a vegetação arbórea existente e cursos d'água e igarapés, especialmente as suas nascentes” (art. 168, $\S 2^{\circ}$ ). (Lei n. $\left.{ }^{\circ} 7.603,1993\right)$.

Tal medida, todavia, não impediu as inúmeras ocupações no entorno do Parque do Utinga, afetando gravemente os mananciais que vem passando por um crescente comprometimento de sua qualidade e o colocando em condições avançadas de eutrofização.

Por fim, visando a evitar o uso e a ocupação do solo que prejudiquem a qualidade ambiental do território municipal, o plano estabeleceu que o Poder Público deveria solicitar à União (Serviço de Patrimônio da União - SPU e Ministério da Marinha) o gerenciamento de suas terras localizadas na orla da baía do Guajará, rio Guamá, canais, manguezais e igarapés” (art.263). A gestão da propriedade fundiária dessas parcelas, denominadas de terrenos de marinha e acrescidos, até o presente são objeto de litígio entre União e Prefeitura de Belém.

\subsection{Plano Diretor do Município de Belém (PDMB) de 2008}

O Plano Diretor do Município de Belém (PDMB), instituído pela Lei nº 8.655 (2008), seguiu as orientações determinadas pela Lei n ${ }^{\circ} 10.257$ (2001), o Estatuto da Cidade, promovendo a discussão com diversos setores da sociedade, mediante a realização de reuniões, audiências públicas temáticas e territoriais.

Da mesma forma que o plano anterior, o problema dos rios urbanos, quanto aos processos de ocupação, tratamento e proteção, é vinculado à temática referente à política de habitação do município. Nesse sentido, o plano estabelece que,

[...] deverá ser criado instrumento próprio para garantir o direito à moradia da população que habita áreas onde não for viável a regularização urbanística e jurídico-fundiária, como as áreas de preservação ambiental, de risco, destinadas a usos públicos imprescindíveis e non aedificandi, como o leito de cursos d'água, além de instituir um plano de reassentamento (Lei $\mathrm{n}^{\mathrm{o}} 8.655,2008$ ).

É importante observar que, agora, o plano diretor passa a considerar, de maneira explícita, as relações socioeconômicas que a comunidade mantém nestas áreas, deixando claro que, junto à necessidade de recuperação do ambiente, o processo de reassentamento da população deve ser feito para áreas próximas ao assentamento original, assegurando a manutenção de laços socioeconômicos e de vizinhança da população afetada.

Os rios urbanos também são tratados na política municipal de saneamento ambiental, onde novamente é estabelecida a adoção das bacias hidrográficas como unidades de planejamento. Além disso, são previstos a ampliação de medidas de saneamento básico para áreas deficitárias e o controle do uso e da ocupação de margens de cursos d'água, das áreas sujeitas à inundação, de mananciais, de recargas, de alta declividade e nas cabeceiras de drenagem.

Ainda com as finalidades de garantir a proteção e a preservação dos mananciais e de proporcionar a eficiência dos serviços de abastecimento de água, o plano institui que o município deve divulgar e difundir políticas de conservação e uso da água nas bacias hidrográficas, assim como adotar mecanismos de gestão dos resíduos gerados nos sistemas de abastecimento de água.

Com relação à contaminação hídrica pelo esgotamento sanitário inadequado, o estipulou que o município deveria garantir à população o acesso à coleta, ao transporte e ao tratamento adequado dos esgotos, reduzindo os riscos ambientais, os índices de 
doenças de veiculação hídrica, ou relacionadas ao saneamento. Vale ressaltar que, em 2017, na capital paraense, apenas 12,99\% dos habitantes possuíam acesso aos sistemas de esgotamento sanitário; o esgoto tratado era privilégio somente de 0,98\% dos domicílios, configurando um cenário de precariedade alarmante. É o que aponta Ranking da Universalização do Saneamento divulgado pela Associação Brasileira de Engenharia Sanitária e Ambiental (ABES), que avalia a situação das cidades com mais de 100 mil habitantes a partir dos dados enviados ao Sistema Nacional de Informações sobre Saneamento (SNIS), do governo federal (Associação Brasileira de Engenharia Sanitária e Ambiental [ABES], 2019)

No que diz respeito à política de drenagem, o PDMB de 2008 estabeleceu a necessidade de elaboração de planos diretores de drenagem para todas as bacias hidrográficas, assim como de plano de controle de águas pluviais e enchentes, de modo a permitir o escoamento das águas pluviais em toda a área ocupada, propiciando a recarga dos aquíferos, a segurança e o conforto aos seus habitantes. Dentre as ações prioritárias no manejo das águas pluviais, destacou a implantação de medidas de prevenção de inundações, mediante controles de erosão, de transporte, de deposição de resíduos sólidos, e o combate ao desmatamento.

Sobre a contaminação dos rios urbanos promovidas pelo lançamento inadequado de resíduos sólidos, o plano traz uma subseção inteira de orientações, apontando ações como as de educação ambiental, oferta de instalações para disposição de resíduos sólidos e fiscalização efetiva.

O plano de 2008 também considera os rios urbanos enquanto canais de deslocamento relevantes para fluxos no interior e intermunicipais de pessoas e mercadorias. Ao tratar da mobilidade urbana, prevê no art. 42, a "ampliação da acessibilidade interna nas ilhas por meio da melhoria de circulação viária e do ordenamento dos diversos modos de circulação" (Lei no 8.655, 2008). Entretanto, o plano não coloca o sistema hidroviário integrado ao sistema de mobilidade urbana, no art. 45, onde trata do tema. Essa omissão constitui uma lacuna. A bacia do Tucunduba, por exemplo é importante rota de navegação intraurbana. Nela, várias embarcações: transportam grande variedade de produtos que abastecem a feira do bairro da Terra Firme; escoam a produção de serrarias localizadas na margem; e promovem a locomoção de pessoas do entorno do canal para ilhas localizadas do outro lado da baía do Guajará (Costa \& Pontes, 2019).

Ao dispor sobre a Política Municipal de Meio Ambiente o plano admite que rios "são importantes corredores biológicos que permitem a frequência e a circulação da flora e da fauna no interior da cidade" (Costa, 2006, p. 10) e institui corredores de integração ecológica ao longo da rede hídrica municipal, objetivando, entre outros, propiciar e estimular transformações urba nas estruturais visando a um processo de desenvolvimento sustentável e recuperar áreas ambientalmente degradadas junto aos cursos d'água (Lei no $8.655,2008)$.

Vale salientar que a importância que o plano confere aos recursos hídricos não se restringe às políticas setoriais (habitacional e ambiental). Ao definir a estrutura espacial e o zoneamento do município, considera a rede hídrica da cidade como o mais importante sistema estruturador do ordenamento territorial urbano. Além disso, estabelece diretrizes específicas para macrozonas e zonas urbanas e especiais relacionadas aos rios e orlas urbanos.

No macrozoneamento, determina como diretrizes para a Macrozona do Ambiente Urbano (MZAU) - correspondente às áreas urbanizadas do território - o resgate das áreas da orla fluvial, das praias e margens dos cursos d'água, objetivando a proteção e preservação do meio ambiente. No zoneamento ordinário, por exemplo, estabelece para a Zona do Ambiente Urbano 5 (ZAU-5) a contenção da ocupação nas áreas de entorno dos canais. Essa zona é caracterizada por apresentar: predomínio do uso residencial; alta densidade populacional associada a carências infra estruturais e de equipamentos públicos; elevada incidência de ocupação precária, com núcleos habitacionais de baixa renda; e, risco de alagamento.

Para o Parque Ambiental do Utinga (Setor I da Zona de Ambiente Natural - ZAN 1), o plano traça como diretrizes: 
viabilizar ações de recuperação e conservação dos lagos Água Preta e Bolonha; recuperar as áreas degradadas, conservando a biodiversidade existente; e, promover o remanejamento da população residente na área do Parque.

A criação de mecanismo de monitoramento da margem do rio Guamá evitando a ocupação da ZAN 1 - Setor II, é uma das diretrizes para a área sul da APA-Belém, onde estão as bacias hidrográficas tributárias do rio Guamá, portos, áreas antropizadas e ocupações irregulares, além de instituições públicas de ensino e pesquisa, do centro de abastecimento alimentar e do sistema de captação e adução de águas.

Interessante observar que há, nos dispositivos do plano, uma evidente preocupação não apenas em preservar e recuperar os cursos d'água que sofrem com a ocupação desordenada, mas também em proteger ambientes ainda conservados.

\section{Considerações Finais}

Os rios urbanos são importantes condicionantes da morfologia urbana, dos usos e da ocupação do solo no território. Não obstante, é a sociedade, mediante processos de produção, apropriação e consumo do espaço que define como esse recurso natural é apropriado, consumido e transformado.

Em sociedades capitalistas - onde a produção do espaço urbano se faz sob a lógica do lucro, da captura da renda fundiária e da financeirização da economia, a luta pelas melhores localizações configura espaços desiguais. Nesse contexto, os rios e suas margens deixam de ser um mero recurso natural e passam a desempenhar novos, diversificados e complexos papéis, inclusive como oportunidade para investimentos e reprodução ampliada do capital (financeiro, turístico, indústria da construção civil, transporte etc.).

Desde a promulgação da Constituição Federal (1988), cabe ao conjunto da sociedade definir a função social dos diversos espaços urbanos, enfrentando os desafios da promoção do uso e da ocupação do solo urbano ambientalmente adequado, da promoção da infraestrutura de saneamento básico e da redução dos elevados déficits (quantitativo e qualitativo) de habitação para população de baixa renda. O principal instrumento disponibilizado para isso, no Brasil, é o Plano Diretor, que deve ser elaborado com a participação da sociedade e aprovado pela Câmara Municipal.

As funções desempenhadas pelos rios na cidade e a maneira pela qual eles vêm sendo tratados nas intervenções, no planejamento urbano e nos Planos Diretores Municipais, assumem então relevância especial, sobretudo para as cidades da Amazônia, região que concentra $20 \%$ da água doce disponível no planeta.

A análise dos Planos Diretores do Município de Belém de 1993 e de 2008 revelou haver uma tendência de a problemática dos rios urbanos ampliarem sua importância, quer seja mediante a progressiva associação aos problemas intraurbanos de habitação, saneamento, escassez de áreas de lazer etc., quer seja por meio da exploração da sua paisagem como estratégia para a inserção competitiva da cidade ao turismo globalizado.

Numa cidade como Belém - onde, dos 33 bairros da região continental, 21 deles são costeiros e sujeitos à inundação por estarem abaixo da cota de maré cheia (Rodrigues, Tavares \& Miranda, 2016) e em que as terras centrais, de cotas altas e secas, são escassas e caras -, fica evidente a necessidade dos Planos Diretores Municipais e das intervenções urbanas buscarem equilíbrio entre ocupação urbana e natureza, em especial no que concerne aos rios urbanos.

Mas, a solução dos problemas não é simples. Às inúmeras dificuldades técnicas-ambientais, agregam-se outras, como: a dependência de recursos de agências de financiamento para prover a demanda de novas moradias e de obras de saneamento; a complexidade envolvida nas ações de remanejamento de comunidades pobres, dentre outros motivos, pelos impactos negativos do 
rompimento das relações de solidariedade construídas nesses grupos sociais envolvidos nessas medidas.

Diante disso, na grande maioria dos cursos d'agua de Belém, as diretrizes dos planos diretores não se converteram em ações implementadas, mantendo-se a ocupação irregular e a necessidade de melhorias dos canais como alguns dos grandes problemas a serem enfrentados para o desenvolvimento urbano.

Certamente, o equilíbrio entre ocupação urbana e natureza ainda demanda um longo caminho. No entanto, Belém precisa iniciar esta caminhada. É preciso lembrar sempre que a convivência harmoniosa com a água é fundamental para que os rios urbanos continuem a existir. Somente essa convivência fará com que a população se aproprie desses espaços e garanta o êxito do planejamento urbano e ambiental.

Por fim cabe destacar que as alternativas para solucionar o problema dos rios urbanos em Belém vão além do discurso dos planos, embora deles não prescinda, pois é neles que se define a função social da cidade, da propriedade urbana e a relação com os recursos hídricos.

Nesse sentido, é necessário ampliar a perspectiva de análise dos rios urbanos nos planos diretores, considerando a ocupação das margens por habitação de famílias pobres e as carências de saneamento básico, sem reduzir os problemas dos rios urbanos a essas causas. A ocupação e o lançamento de esgotos domésticos se fazem por todas as camadas da sociedade; a apropriação e o uso inadequado dos rios e suas margens também são realizados por grandes empreendimentos habitacionais destinados a outras camadas de renda, por indústrias, atividades de comércio e serviços de diversas naturezas. Esses fatos não podem ser obliterados no debate, nem omitidos nas ações corretivas.

Sugere-se um amplo estudo de como ocorreu a ocupação literal dos cursos d'água (e suas margens) ao longo dos anos e se a ausência de planejamento, gestão e fiscalização na proteção dos recursos hídricos pode ter sido responsável por diversas questões sociais, econômicas e ambientais que a Região Metropolitana de Belém atualmente enfrenta.

\section{Referências}

ABES. (2020). Ranking Abes da Universalização do Saneamento 2019. http://abes-dn.org.br/pdf/Ranking_2019.pdf.

Arruda, E. S. (2003). Porto de Belém do Pará: origens, concessão e contemporaneidade. Dissertação de Mestrado em Planejamento Urbano e Regional, Universidade Federal do Rio de Janeiro, Rio de Janeiro, RJ, Brasil.

Becker, B. (1990). Amazônia. São Paulo: Ática.

Belém. (2019). Anuário Estatístico do Município de Belém - 2019. http://anuario.belem.pa.gov.br/.

Belém. (2019). Bacias Hidrográficas. Prefeitura de Belém http://www.belem.pa.gov.br/app/c2ms/v/?id=18\&conteudo=475.

Diagnóstico Habitacional de Belém. Prefeitura de Belém (2008). http://planodiretor.belem.pa.gov.br/wp-content/uploads/2019 /05/Diagnostico-Habitacion al-de-Belem_2008.pdf.

Lei $\mathrm{n}^{\circ}$ 7.603, de 13 de janeiro de 1993 (1993). Institui o Plano Diretor do Município de Belém. http://planodiretor.belem.pa.gov.br/wp-conten t/uploads/2019/08/Lei-7603_13-01--Plano-Diretor-Urbano-de-Belem_PDU.pdf.

Lei $\mathrm{n}^{\circ}$ 8655, de 30 de julho de 2008 (2008). Institui o Plano Diretor do Município de Belém. http://www.belem.pa.gov.br/planodiretor/ Plano_diretor_atual/Lei_N865508_plano_diretor.pdf.

Braga, R. da C., Barbosa, A. L. das C., \& Almeida, L. S. (2014). Urbanização e áreas de alagamentos em Belém: Estudo da bacia da Estrada Nova. Anais do Congresso Brasileiro de Geógrafos, Vitória, ES, Brasil, 7.

Constituição da República Federativa do Brasil (1988). http://www.planalto.gov.br/ccivil_03/constituicao/constituicao.htm.

Lei $n^{\circ}$. 10.257, de 10 de julho de 2001 (2001). Regulamenta os artigos 182 e 183 da Constituição Federal, estabelece diretrizes gerais da política urbana e dá outras providências. http://www.planalto.gov.br/ccivil_03/leis/leis_2001/110257.htm.

Lei $n^{o} .9 .433$ de 08 de janeiro de 1997 (1997). Institui a Política Nacional de Recursos Hídricos. http://www.planalto.gov.br/ccivil_03/LEIS/L9433.htm. 
Lei no.12.608 de 10 de abril de 2012 (2012). Institui a Política Nacional de Proteção e Defesa Civil - PNPDEC. http://www.planalto.gov.br/cci il_03/_Ato2011-2014/2012/Lei/L12608.htm.

Carvalho, M. E. S. (2015). Riscos e vulnerabilidades socioambientais na bacia costeira do rio Vaza Barris/Sergipe/Brasil: Contribuições para o planejamento e gestão ambiental. Anais Congresso sobre Planeamento e Gestão das Zonas Costeiras dos Países de Expressão Portuguesa. 8.

Castro, E. (2019). Belém do Grão-Pará: de águas e de mudanças nas paisagens. In e. Stoll (org.). Paisagens evanescentes: estudos sobre a percepção das transformações nas paisagens pelos moradores dos rios Amazônicos. NAEA/UFPA.

Conti, A., \& Silva, P. H. P. (2018). As múltiplas escalas da reconciliação "Rio-Cidade”: Ideias e Soluções replicáveis para a microbacia São José-Itabirito, MG. Encontro Nacional da Associação Nacional de Pós-graduação e Pesquisa em Planejamento Urbano e Regional. São Paulo, Brasil, 17.

Corrêa, A. J. L. (1989). O espaço das ilusões: planos compreensivos e planejamento urbano na Região Metropolitana de Belém. Belém, 1989. Dissertação de Mestrado em Planejamento em Desenvolvimento, Universidade Federal do Pará, Belém, PA, Brasil.

Correa, R. L. (2006). A periodização da rede urbana amazônica. In R. L. Corrêa (org.). Estudos sobre a rede urbana. Bertrand do Brasil.

Costa, A. N., \& Pontes, W. R. (2019). Uso de indicadores de Saneamento Ambiental, na Bacia Hidrográfica do Tucunduba, visando a Redução das Doenças de Veiculação Hídrica. Trabalho de Conclusão de Curso, Instituto Federal de Educação, Ciência e Tecnologia do Pará, Belém, PA, Brasil.

Costa, L. M. S. A. (2006). Rios e paisagens urbanas em cidades brasileiras. Viana \& Mosley, Editora PROURB.

Costa, M. J. B. (2018). Planejamento e Gestão Urbana na Orla de Belém (PA): Análise do Complexo Ver-o-Rio. AOS - Amazonia, Organizações e Sustentabilidade. AOS, Brazil, 7(2), 99-110.

DOL. (2019). Audiência Pública debate construção de supermercado no Portal da Amazônia. https://www.diarioonline.com.br/noticias/para/54336 0/audiencia-publica-d ebate-construc ao-de-supermercado-no-portal-da-amazonia.

Lakatos, E. M. \& Marconi, M. A. Fundamentos de Metodologia Científica. (5a ed.), Atlas.

McHarg, I. L. (1971). Design with nature. Doubleday/National History Press.

Mendonça, F. de A., \& Leitão, S. A. M. (2008). Riscos e vulnerabilidade socioambiental urbana: uma perspectiva a partir dos recursos hídricos. GeoTextos, 4(1), $145-163$

Nascimento, E. (2014). Conheça o parque Zoobotânico Mangal das Garças, no Pará. https://fotospublicas.com/conheca-o-parque-zoobotanico-man gal-das-garcas-para/.

Oliveira, J. A. (2006). A cultura, as cidades e os rios na Amazônia. Ciência e Cultura, 58(3).

Penteado, A. R. (1968). Belém do Pará: estudo de geografia urbana. UFPA - Imprensa Universitária.

PARATURISMO. (2018). Estação das Docas. http://www.paraturismo.pa.gov.br/vejamais_negocios_eventos/belem/estacao.

Ponte, J. P. X. (2007). Cidade e água: Belém do Pará e estratégias de reapropriação das margens fluviais. Arquitextos, $08(2)$. Recuperado em 29 de janeiro de 2020 de: <https://www.vitruvius.com.br/revistas/read/arquitextos/08.085/237>.

Ponte, J. P. X. (2020). Belém do Pará: cidade e água. Cadernos Metrópole. 17(33).

Rodrigues, R. M., Tavares, A. C. M., \& Miranda, T. B. (2016). Urbanizar as "baixadas": experiências de projetos de urbanização de assentamentos precários em áreas de preservação permanente em Belém ( $\mathrm{Pa}$ ). Anais do Encontro da Associação Nacional de Pesquisa e Pós-Graduação em Arquitetura e Urbanismo, Porto Alegre, RS, 20.

ROMANEWS. (2019). Adolescente de 15 anos morre afogado no Ver-O-Rio. https://www.romanews.com.br/cidade/adolescente-de-15-ano s-morre-afogado-no-ver-o-rio/39943/.

ROMANEWS. (2020). Placas de carro são encontradas boiando após canal da Doca transbordar. https://www.romanews.com.br/c idade/placas-de-carros-sao-encontradas-boiando-apos-canal-da-doca/71921/.

Sarges, M. de N. (2002). Belém: riquezas produzindo a Belle-Époque (1870-1912). Paka-Tatu.

Santos, E. R. C. (2016). História da cidade de Belém: intervenções urbanísticas e produção do espaço da orla fluvial. Anais Encontro Nacional de Geógrafos. São Luís, MA 18.

Spirn, A. W. (1984). The granite garden. Urban nature and human design. La Verne/TN (EUA), Basic Books.

Tourinho, H. L. Z. (2011). Estrutura urbana de cidades médias amazônicas: análise considerando a articulação das escalas interurbana e intraurbana. Tese de Doutorado, Universidade Federal de Pernambuco, Programa de Pós-Graduação em Desenvolvimento Urbano, Recife. 
Research, Society and Development, v. 10, n. 10, e591101019159, 2021

(CC BY 4.0) | ISSN 2525-3409 | DOI: http://dx.doi.org/10.33448/rsd-v10i10.19159

Trindade, S. C. C., \& Tavares Junior, M. G. C. (2008). Cidades Ribeirinhas da Amazônia: mudanças e permanências. EDUFPA.

Vainer, C. (2000). Pátria, empresa e mercadoria. Notas sobre a estratégia discursiva do Planejamento Estratégico Urbano. In O. Arantes, C. Vainer \& E. Maricato (Orgs.) A cidade do pensamento único: desmanchando consensos. 1, Cap. 2, 75-104. Vozes.

Vitale, S. P. de S. M. (2015). Caminhos para uma gestão integrada: Aproximação e conflito entre planos hídricos e plano urbano em Guaratinguetá, SP. Fórum Ambiental da Alta Paulista, 11(6), 337-348. 